\title{
Mineração de Dados Educacionais para Geração de Alertas em Ambientes Virtuais de Aprendizagem como Apoio à Prática Docente
}

\author{
Adriana Justin Cerveira Kampff \\ Orientador(a): Prof. Dr. José Valdeni Lima \\ Coorientador: Prof. Dr. Eliseo Berni Reategui \\ Data da defesa: 21 de dezembro de 2009
}

A Educação a Distância (EAD) no país apresenta-se em franca expansão. Cresce, a cada dia, o número de alunos que estudam por meio dessa modalidade. Gerenciar seus processos de aprendizagem em Ambientes Virtuais de Aprendizagem (AVA), com qualidade de interação e de acompanhamento, exige cada vez mais do professor. Esta tese descreve uma pesquisa que identifica, por meio de Mineração de Dados (MD) gerados pela interação em AVA, comportamentos e características de alunos com risco de evasão ou reprovação e, então, alerta o professor. Tais alertas são gerados a partir de agrupamentos de alunos com características similares, para que o professor possa estabelecer comunicação personalizada e contextualizada com esses sujeitos. O trabalho propõe uma arquitetura para sistemas de alertas em AVA, com alertas pré- definidos e outros gerados a partir da mineração de dados. Para validação da arquitetura, foram utilizados dados de 1564 alunos, de edições anteriores de uma mesma disciplina a distância, para mineração e extração de regras de classificação. As regras foram aplicadas para gerar os alertas durante o acompanhamento de 230 alunos em turmas em andamento. De cada aluno, cerca de 230 atributos foram analisados. Ao final, foi possível comprovar que as intervenções realizadas pelo professor, a partir dos alertas, direcionadas a grupos que compartilhavam necessidades específicas, contribuíram para a melhoria dos índices de aprovação e para redução dos índices de evasão dos alunos na disciplina acompanhada.

Palavras-chave: Ambientes Informatizados de Aprendizagem. Mineração de Dados. Mediação em EAD.

Referência:

KAMPFF, Adriana Justin Cerveira. A Gestão em cursos de educação a distância via Internet: uma visão a partir dos fatores críticos de sucesso - Orientador: José Valdeni Lima. Coordenador: Eliseo Berni Reategui - 2009. Tese (doutorado) - Programa de Pós-Graduação em Informática na Educação, Centro de Estudos Interdisciplinares em Novas Tecnologias da Educação, Universidade Federal do Rio Grande do Sul, 2009, Porto Alegre, BR-RS. 